\title{
EVOLUÇÃO DE DANOS DURANTE ENSAIO DE TRAÇÃO DO AÇO INOXIDÁVEL AISI $444^{1}$
}

\author{
Fernando Victor Nery ${ }^{2}$ \\ Leonardo Barbosa Godefroid ${ }^{3}$ \\ Geraldo Lúcio de Faria ${ }^{4}$
}

\section{Resumo}

Neste trabalho, uma análise detalhada do mecanismo de fratura durante ensaio de tração foi conduzida para um aço inoxidável do tipo AISI 444. Os materiais utilizados para a realização dos procedimentos experimentais foram 25 corpos de prova usinados no sentido de laminação. Cada um dos corpos de prova foi submetido a procedimentos padrão de lixamento e polimento. Uma amostra foi estruturalmente caracterizada por meio da técnica de microscopia óptica de luz refletida para análise do estado de entrega. As demais foram submetidas a ensaios de traçãocom taxa de aplicação de carga constante. Três amostras foram submetidas ao ensaio completo (até a fratura) e as demais até valores específicos de deformação, onde o ensaio foi interrompido e as amostras caracterizadas por microscopia ótica e microscopia eletrônica de varredura, com o objetivo de avaliar a evolução de danos e identificar o mecanismo de fratura nas condições testadas. Foi proposta uma metodologia de quantificação de danos por meio da rugosidade superficial identificada pela microscopia óptica. Este índice foi denominado "Índice de Danos por Reflexão Difusa" (IDRD). Por meio da utilização desta metodologia foi possível quantificar a evolução de danos em função da deformação do corpo de prova. Por meio das análises de microscopia eletrônica de varredura foi possível observar que o mecanismo de deformação predominante foi o de nucleação, crescimento e coalescimento de microcavidades, resultando em uma fratura dúctil.

Palavras-chave: Ensaio de tração; Mecanismos de fratura; Fratura dúctil; Evolução de danos.

\begin{abstract}
DAMAGE EVOLUTION IN STAINLESS STEEL AISI 444 DURING TENSION TEST
Abstract

This paper presents a study about the fracture mechanism of the stainless steel AISI 444 during tension test. The applied materials for the experimental procedures were 25 specimens of the stainless steel AISI 444 machined in the rolling direction. Each specimen were submitted to standardized polishing procedures. One of the samples, in the original state, was structurally characterized by reflected light optical microscopy. The others samples were submitted to the tension tests with constant charge application rate. Three samples were tested until the failure (complete testes) and the others just until specific deformation values, when the test was interrupted and the samples were characterized by using optical microscopy and scanning electron microscopy. The main objective of these characterizations was to evaluate the structural damage evolution and to identify the fracture mechanism for the testes conditions. A quantitative method was proposed aiming to quantify the damage evolution by the surface roughness evaluated by optical microscopy. A new index was proposed: Damage by Diffuse Reflection Index (DDRI). Applying this method it was possible to quantify the damage evolution in function of the specimen final deformation. It was possible to conclude that the main fracture mechanism was the microvoids nucleation, growth and coarsening resulting in a ductile failure.
\end{abstract}

Keywords: Tension test; Fracture mechanism; Ductile failure; Damages evolution.

1 Contribuição técnica ao $68^{\circ}$ Congresso Anual da ABM - Internacional, 30 de julho a 2 de agosto de 2013, Belo Horizonte, MG, Brasil.

2 Graduando em Engenharia Metalúrgica. UFOP, Ouro Preto, MG, Brasil. fvnery@hotmail.com.

3 Engenheiro Metalurgista. Dr. Professor. Departamento de Engenharia Metalúrgica e de Materiais (DEMET), UFOP, Ouro Preto, MG, Brasil. leonardo@demet.em.ufop.br.

4 Físico. Dr. Professor. Departamento de Engenharia Metalúrgica e de Materiais (DEMET), UFOP, MG, Brasil; geraldofaria@demet.em.ufop.br 


\section{INTRODUÇÃO}

A descrição dos aspectos microestruturais associados à fratura dos materiais tem sido tema de importantes trabalhos científicos desde a década de 1950. Um assunto extensamente investigado é a descrição dos mecanismos de iniciação e evolução da fratura dúctil em metais e ligas. Uma revisão bibliográfica geral sobre a fratura dúctil pode ser encontrada nos trabalhos de Rosenfield, ${ }^{(1)}$ Low Junior, ${ }^{(2)}$ Schwalbe, ${ }^{(3)}$ Howard e Willoughby, ${ }_{(4)}$ Wilsdorf, ${ }^{(5)}$ Van Stone et al. ${ }^{\left({ }^{(6)}\right.}$ Godefroid e Bastian. ${ }^{(7)}$

Puttick, ${ }^{(8)}$ Rogers ${ }^{(9)}$ e Chen ${ }^{(10)}$ mostraram pioneiramente que a fratura dúctil tem início com a nucleação e crescimento de vazios preferencialmente em partículas de segunda-fase, contornos de grão ou qualquer outra região onde se observe heterogeneidade estrutural. Beevers e Honeycomb, ${ }^{(11)}$ estudando alumínio e cobre puros nas suas formas monocristalinas e policristalinas, conseguiram mostrar que microscopicamente é possível observar, dentro de um grão deformado, linhas paralelas que estão associadas ao escorregamento de planos em uma direção preferencial, e que para elevados graus de deformação, há formação de vazios a partir destas linhas, então denominadas bandas de deformação.

A partir de trabalhos fundamentais, diversos pesquisadores passaram a descrever os mecanismos de fratura e a evolução microestrutural de ligas metálicas comerciais quando submetidas à deformação plástica. Muitos trabalhos fizeram uso do ensaio mecânico de tração como ferramenta de deformação plástica controlada dos materiais. Edelson e Baldwin ${ }^{(12)}$ mostraram que a redução da área transversal do corpo de prova de tração é drasticamente reduzida á medida que se trabalha com ligas com frações crescentes de segunda fase, pois isto aumenta os prováveis pontos de nucleação de microcavidades e fragiliza o material. Low ${ }^{(2)}$ mostrou que as observações de Edelson e Baldwin ${ }^{(12)}$ estavam coerentes e que, a depender da densidade de microcavidades, a fratura do material pode deixar de ser dúctil e se tornar frágil, com aspecto macrográfico planar.

Cox e Low ${ }^{(13)}$ descrevendo a evolução microestrutural do aço AISI 4340 mostraram que quanto maior a deformação real experimentada pelo corpo de prova durante ensaio de tração, maior é a fração de microcavidades nucleadas nas inclusões do aço em questão. Os autores também estudaram a influência da fração de inclusões do aço sobre a densidade de microcavidades e a deformação final suportada pelo material antes da ruptura. Eles mostraram que quanto maior a fração de inclusões, maior é a taxa de nucleação de microcavidades, portanto menor é a deformação total suportada pelo corpo de prova.

Argon e Needeman ${ }^{(14)}$ e Argon $^{(15)}$ estudaram a nucleação de microcavidades em um aço maragin grau 300, em um aço AISI 1045 e em uma liga Cu-0,6Cr. Eles utilizaram corpos de prova convencionais e providos de entalhe e mostraram que a presença de entalhe fragiliza os materiais estudados. Por meio de modelos gerados com o auxílio do método de elementos finitos, eles mostraram que a taxa de nucleação das microcavidades está relacionada com a fração de heterogeneidades estruturais e com um critério de tensão interfacial entre as fases presentes.

Alguns pesquisadores descreveram também o crescimento e coalescimento das microcavidades, que consiste basicamente em um processo de crescimento dos microvazios em função da elevada deformação plástica localizada. Shockey, Seaman e $\mathrm{Dao}^{(16)}$ estimaram que mais de $87 \%$ da energia consumida durante a ruptura de um corpo de prova é consumida durante a etapa de crescimento das microcavidades. Floreen e Hayden, ${ }^{(17)}$ estudando um aço maragin, mostraram que os vazios crescem mais rapidamente se o aço for completamente envelhecido (limite de 
resistência de $1380 \mathrm{MPa}$ ) do que se ele não for envelhecido (limite de resistência de $620 \mathrm{MPa})$.

O último estágio da fratura por dimples é o coalescimento dos vazios, que é o estágio mais difícil de examinar experimentalmente. Cottrell ${ }^{(18)}$ sugeriu que o coalescimento das cavidades poderia ocorrer pela diminuição da espessura da matriz entre os dois pontos de defeito em metais muito dúcteis. Rogers ${ }^{(9)} \mathrm{e}$ Druyresteyn et al. ${ }^{(19)}$ propuseram que o coalescimento poderia ocorrer pela formação de diversas cavidades secundárias nas bandas de intenso cisalhamento entre duas cavidades maiores. A descrição mais satisfatória deste estágio veio com os trabalhos de Crussard et al. ${ }^{(20)}$ onde eles mostraram que o coalescimento pode ocorrer por três modos: a) crescimento das cavidades maiores, b) cisalhamento da matriz entre as cavidades ou c) rasgamento das cavidades.

Atualmente, com o desenvolvimento tecnológico de novos aços, alguns pesquisadores como Kadkhodapour, Butz e $\operatorname{Rad}^{(21)}$ têm se preocupado em descrever os mecanismos de fratura dos mesmo quando submetidos a deformação plástica induzida por tração. Kadkhodapour, Butz e Rad ${ }^{(21)}$ estudaram o mecanismo de fratura de um aço dual-phase por meio da evolução microestrutural em função de diferentes deformações experimentadas por um corpo de prova de tração. Eles mostraram que o mecanismo de fratura neste tipo de aço é influenciado pela deformação localizada originada a partir de heterogeneidades presentes na estrutura do material. Eles afirmam que, para o aço estudado, a nucleação de microcavidades se dá preferencialmente nos contornos de grão da martensita, sendo a morfologia deste constituinte um fator impactante sobre a acumulação de danos na estrutura.

Neste contexto, este trabalho propõe um estudo descritivo a respeito da evolução de danos em um aço inoxidável ferrítico do tipo AISI 444 submetido a ensaio de tração. Este aço tem grande importância comercial ${ }^{22)}$ e a descrição aqui proposta consiste em avaliar a sua evolução microestrutural em função de diferentes deformações aplicadas, buscando caracterizar a nucleação, o crescimento e o coalescimento de microcavidades até a ruptura final. Propõe-se ainda um método experimental, baseado no princípio de reflexão difusa das superfícies, para quantificar os diferentes estágios de danos experimentados pelo material.

\section{MATERIAIS E MÉTODOS}

\subsection{Materiais}

Para o desenvolvimento deste trabalho, foram doados pela empresa APERAM corpos de prova de raio contínuo entre cabeças do aço inoxidável AISI 444 padronizados para ensaio de tração. Para fins de cálculos de tensão convencional, adotou-se uma área útil que corresponde ao centro do corpo de prova. A Tabela 1 apresenta as dimensões dos corpos de prova utilizados, assim como a Figura 1 apresenta uma fotografia de um deles.

Tabela 1 - Dimensões da região útil dos corpos de prova utilizados neste trabalho

\begin{tabular}{|c|c|c|}
\hline Comprimento Útil $\left(\mathbf{L}_{\mathbf{0}}\right)$ & Largura Útil $\left(\mathbf{W}_{\mathbf{0}}\right)$ & Espessura $\left(\mathbf{B}_{\mathbf{0}}\right)$ \\
\hline $50 \mathrm{~mm}$ & $12,5 \mathrm{~mm}$ & $0,5 \mathrm{~mm}$ \\
\hline
\end{tabular}




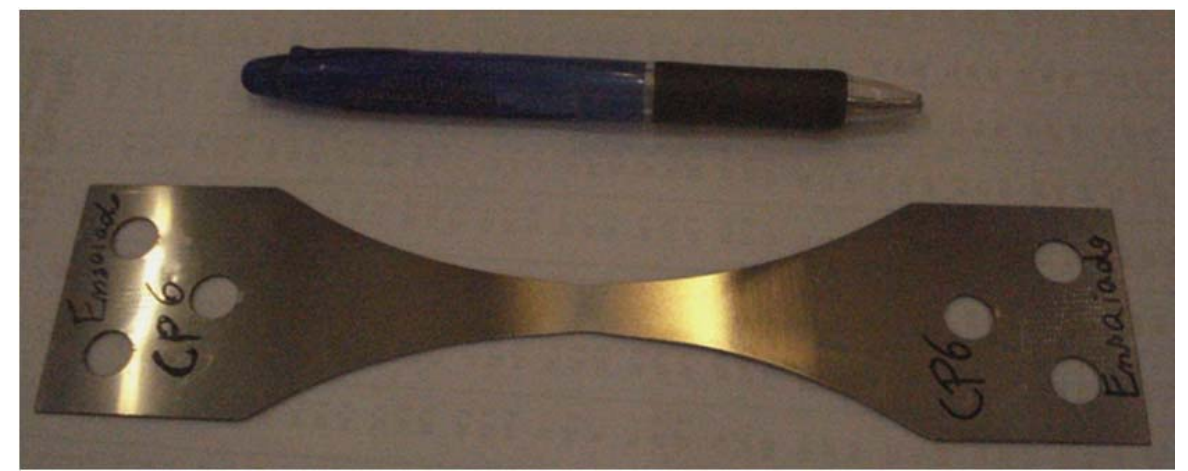

Figura 1 - Fotografia de corpo de prova padrão utilizado no desenvolvimento deste trabalho.

\subsection{Procedimentos Experimentais}

Inicialmente, um dos corpos de prova foi aleatoriamente amostrado para ser submetido a procedimentos padrão de análise química por espectrometria de emissão óptica, em um equipamento modelo ARL4460 da ThermoScientific.

Esta técnica consistiu em submeter a amostra a uma descarga elétrica por eletrodo de tungstênio, provocando vaporização e excitação dos elétrons em uma atmosfera de argônio.Este microplasma formado foi direcionado para uma fenda (sistema óptico) e captado por detectores e fotomultiplicadores. O espectro de radiação detectadofoi eletronicamenteconvertido em valores percentuais de massa dos elementos com espectros característicos correspondentes.

Com o objetivo de se preparar adequadamente os corpos de prova para avaliação da evolução dos danos em função da deformação experimentada nos ensaios de tração, cada um doscorpos de provas foi submetido a uma sequência de procedimentos para sua preparação superficial nos Laboratórios de Tratamentos Térmicos e Microscopia Óptica da Universidade Federal de Ouro Preto (DEMET).

A primeira etapa consistiu no lixamento, que devido à boa qualidade superficial do aço inoxidável em questão, teve início com movimentos periódicos dos corpos de prova na direção perpendicular à direção de laminação sobre uma lixa de 400mesh e na sequência sobre lixas de 600 mesh, 800 mesh e 1200 mesh. Destaca-se que entre cada procedimento de lixamento a amostra experimentou uma rotação de $90^{\circ}$. Após osprocedimentos de lixamento e uma inspeção em microscópio óptico de luz refletida com aumentos de 10X e 100X, as amostras foram submetidas a um procedimento de polimento em suspensão aquosa de alumina com tamanho médio de partículas de $2 \mu$ me em seguidaa um acabamento em pasta de diamante com tamanho médio de partículas de $1 \mu \mathrm{m}$. Após o polimento, as amostras foram submetidas a uma reavaliação da qualidade superficial no microscópio óptico.

O microscópio óticoutilizado para a realização deste trabalho foi um profissional da fabricante LEICA, acoplado a uma câmera para aquisição de imagens do fabricante LECO IA 3001. Esse sistema é acoplado a um computador e a umsoftwarequantitativo (Q-Win) utilizado na aquisição e tratamento das imagens.

Os corpos de prova devidamente polidos foram então submetidos aos ensaios de tração. Inicialmente três deles foram submetidos ao ensaio completo, até a ruptura, para caracterização de seu comportamento sob tração e determinação dos seus principais parâmetros de resistência. Os ensaios foram realizados em uma máquina servo-hidráulica MTS-810 provida de célula de carga com capacidade máxima para 10 toneladas, situada no Laboratório de Ensaios Mecânicos do DEMET/Escola de Minas/UFOP. Todos os ensaios foram realizados à temperatura ambiente e com velocidade de deformação de $5 \mathrm{~mm} /$ minuto. 
Os demais corpos de prova foram submetidos a ensaios de tração incompletos, sendo interrompidos com 1,2\%, 9,7\%, 12,2\%, 14\%, 15,5\% e 16\% de deformação. Cada corpo de prova ensaiado até uma deformação específica foi reservado para avaliação macro e microestrutural sem que experimentasse nenhuma deformação extra. O mesmo sistema óptico já mencionado foi empregado na caracterização da evolução de danos por meio da observação das alterações nas superfícies previamente polidas.

Por meio da utilização de Microscopia Eletrônica de Varredura, foram realizadas análisesmicrográficas dos danos superficiais causados nos corpos de prova não fraturados e microfratográficas daqueles ensaiados até a fratura. O equipamento utilizado foi um MEV Inspect S50, modelo 4.1.4.2010, série D9608. Para a captura de imagens, foi utilizado o software $x T$ Microscope Control.

O software Q-Win foi utilizado para se propor e determinar um parâmetro quantitativo que possibilitasse comparar os danos superficiais dos corpos de provas ensaiados por traçãoem função dos diferentes graus de deformação. A este parâmetro foi dado o nome de Índice de Danos por Reflexão Difusa (IDRD). Para a determinação deste parâmetro,buscou-se quantificar a fração de área da micrografia fora de foco e/ou com coloração escura (baixa intensidade de luz refletida nas lentes objetivas) em relação à área total da imagem. Com o auxílio do software Q-Win,esta região denominada aqui de superfície com reflexão difusa foi automaticamente identificada e sua área quantificada.

Neste contexto,o parâmetro IDRD (Índice de Danos por Reflexão Difusa), foi proposto para quantificar a porcentagem de danos superficiais associados à ocorrência de rugosidade e cavidades.O IDRD foi definido como a fração de superfície com reflexão difusa em relação a área total da micrografia obtida por microscopia óptica com aumento de 200X. A equação 1 expressa o cálculo do índice proposto.

$$
I D R D=\frac{\text { ÁREA COM REFLEXÃO DIFUSA }}{\text { ÁREA TOTAL DA FIGURA }} \times 100
$$

\section{RESULTADOS E DISCUSSÕES}

\subsection{Caracterização Química e Estrutural}

A Tabela 2 apresenta a porcentagem em massa dos principais elementos químicos presentes no aço inoxidável ferrítico AISI 444.Pode-se observar que com exceção do elemento cromo (Cr), cuja concentração deveria estar entre 17,5\% e 19,5\%, os resultados obtidos mostram que o aço estudado atende às especificações apresentadas no catálogo de aços inoxidáveis da empresa fornecedora. ${ }^{(22)}$

Tabela 2 - Composição química (\% em massa) do aço AISI 444 utilizado neste trabalho

\begin{tabular}{|c|c|c|c|c|c|c|}
\hline $\mathbf{C}(\%)$ & $\mathrm{Mn}(\%)$ & $\mathbf{P}(\%)$ & $\mathbf{S}(\%)$ & $\mathrm{Si}(\%)$ & $\mathrm{Ni}(\%)$ & $\mathrm{Cr}(\%)$ \\
\hline 0,007 & 0,162 & 0,0337 & 0,0021 & 0,469 & 0,195 & 16,66 \\
\hline $\mathrm{Mo}(\%)$ & $\mathrm{Al}(\%)$ & $\mathbf{C u}(\%)$ & $\mathbf{V}(\%)$ & $\mathrm{Nb}(\%)$ & $\mathrm{Ti}(\%)$ & $\mathrm{Co}(\%)$ \\
\hline 1,916 & 0,01 & 0,055 & 0,048 & 0,218 & 0,177 & 0,031 \\
\hline
\end{tabular}

A Figura 2a apresenta uma imagem da superfície de um corpo de prova do aço AISI 444 lixado e polido, sem ataque químico. Pode-seobservar inclusões distribuídas por 
toda a matriz ferrítica eausência de trincas ou quaisquer outras descontinuidadesvolumétricas que possam afetar a sua integridade estrutural.

A Figura $2 b$ apresenta a microestrutura ferrítica do aço estudado após ataque com reativo Vilella modificado $(5 \mathrm{~g}$ de ácido pícrico, $100 \mathrm{ml}$ de álcool etílico e $6 \mathrm{ml}$ de ácido clorídrico).Pode-se notar que há uma distribuição heterogênea dos tamanhos de grãos e a presença de inclusões.

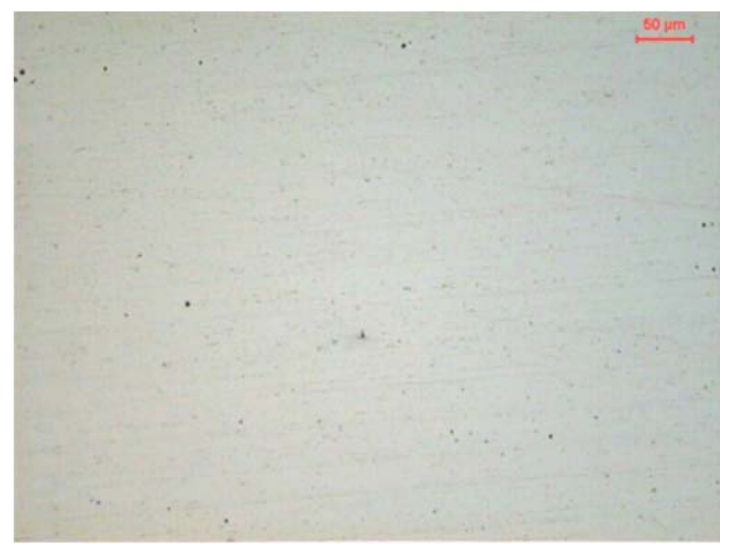

(a)

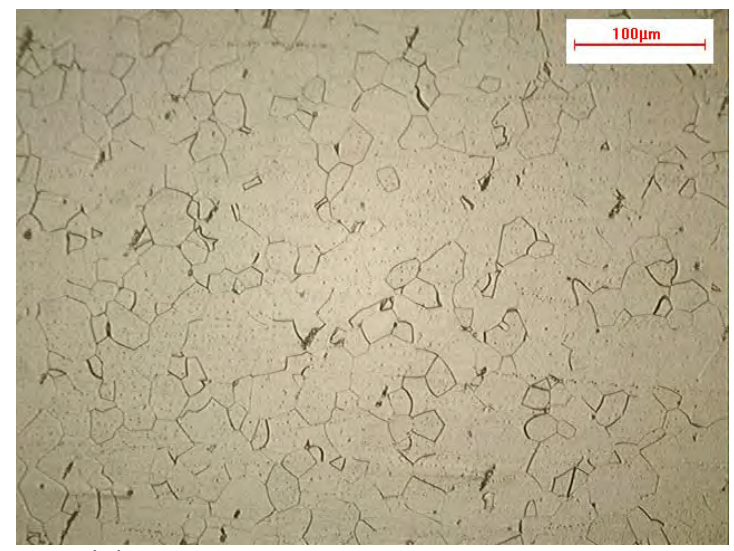

(b)

Figura 2 - (a) Superfície do corpo de prova de tração sem ataque químico, 200X MO. (b)Superfície do corpo de prova de tração atacado quimicamente, $250 \mathrm{X}$ MO.

\subsection{Ensaio de Tração}

A Figura 3 apresenta a curva de engenharia média tensão versus deformação correspondente aos três corpos de prova ensaiados até a fratura. A Tabela 3 apresenta os principais parâmetros médios de resistência e deformação sob tração do aço AISI 444 para o tipo específico de corpo de prova utilizado.

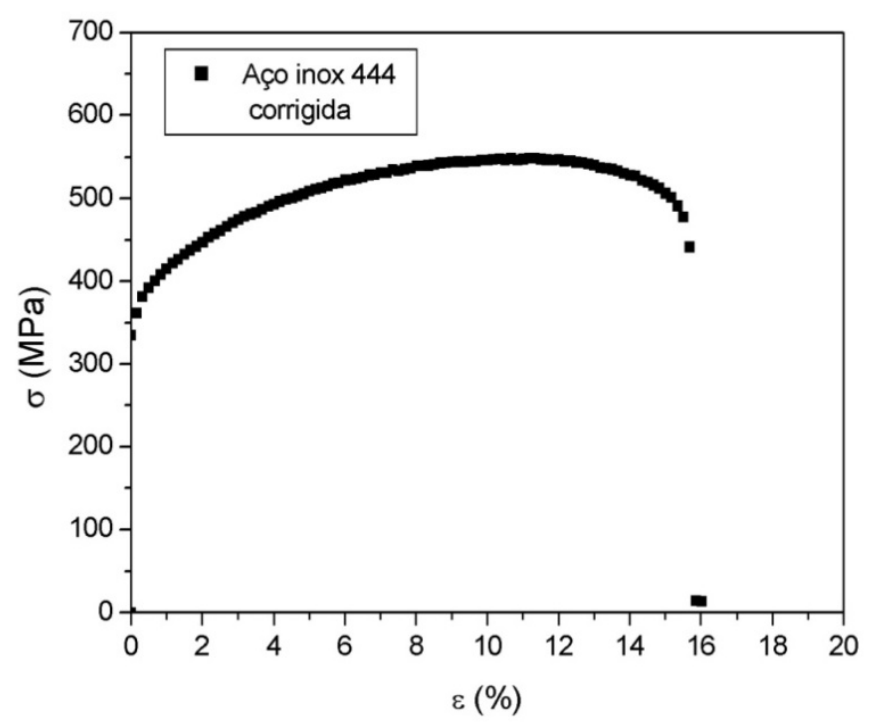

Figura 3 - Curva tensão x deformação corrigida levando em consideração a deformação elástica de componentes da máquina de ensaios (curva "corrigida").

Tabela 3 - Propriedades mecânicas do aço inox 444 obtidas no ensaio de tração (LE - Limite de Escoamento, LR - Limite de Resistência, ALO - Alongamento, RA - Redução de Área)

\begin{tabular}{|c|c|c|c|c|}
\hline Aço/Propriedade & LE (MPa) & LR (MPa) & ALO (\%) & RA (\%) \\
\hline AISI 444 & 334 & 549 & 16 & 36 \\
\hline
\end{tabular}


$68^{\text {th }}$ abm international annual congress

\subsection{Evolução de Danos Sob Tração}

Os corpos de prova ensaiados sob tração até deformações específicas tiveram suas superfícies analisadas por meio de microscopia óptica de luz refletida. As Figuras 4a, 4b, 4c, 4d, 4e e 4f apresentam as micrografias correspondentes aos ensaios com deformação máxima de 1,2\%, 9,7\%, 12,2\%, 14\%, 15,5\% e 16\% respectivamente.

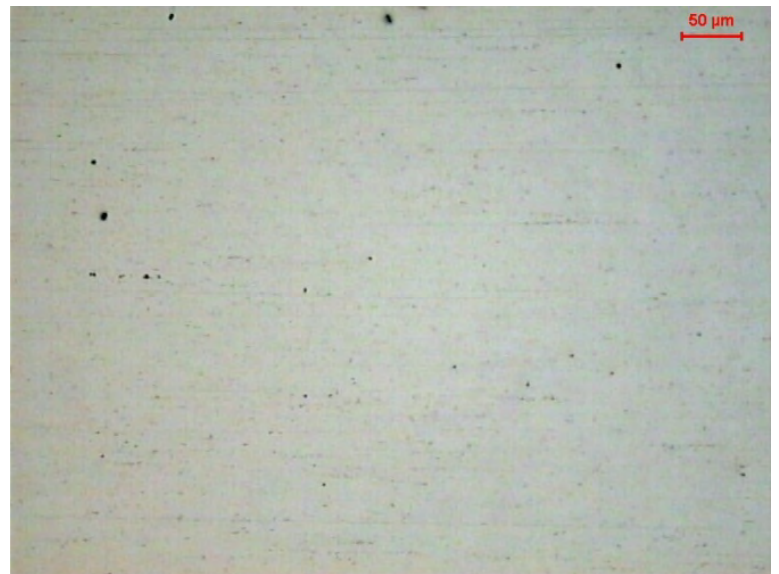

(a)

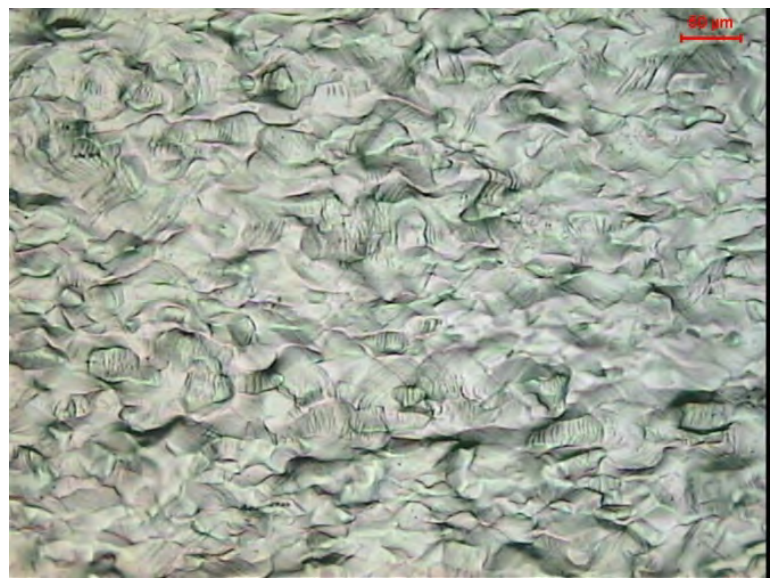

(c)

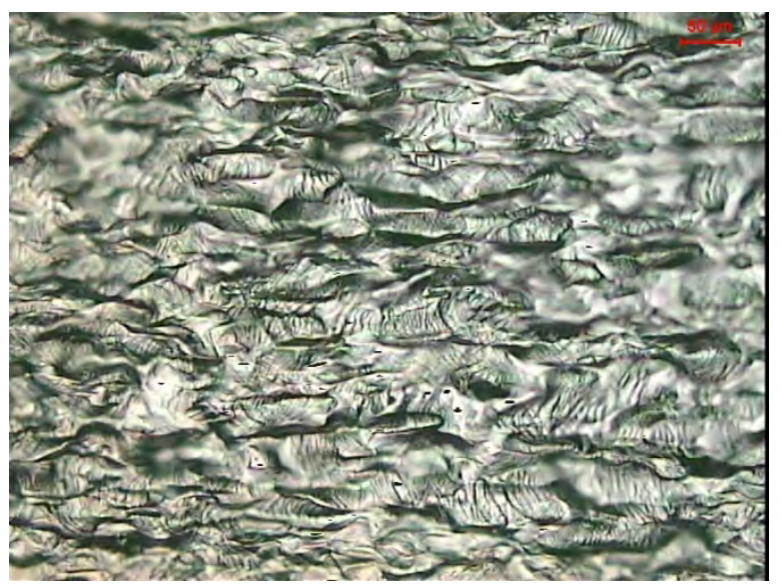

(e)

Figura 4 - Superfícies dos corpos de prova de tração. (a) Deformação de 1,2\%. (b) Deformação de 9,7\%. (c) Deformação de 12,2\%. (d) Deformação de 14\%. (e) Deformação de 15,5\%. (f) Deformação de $16 \%$. 200X. MO.

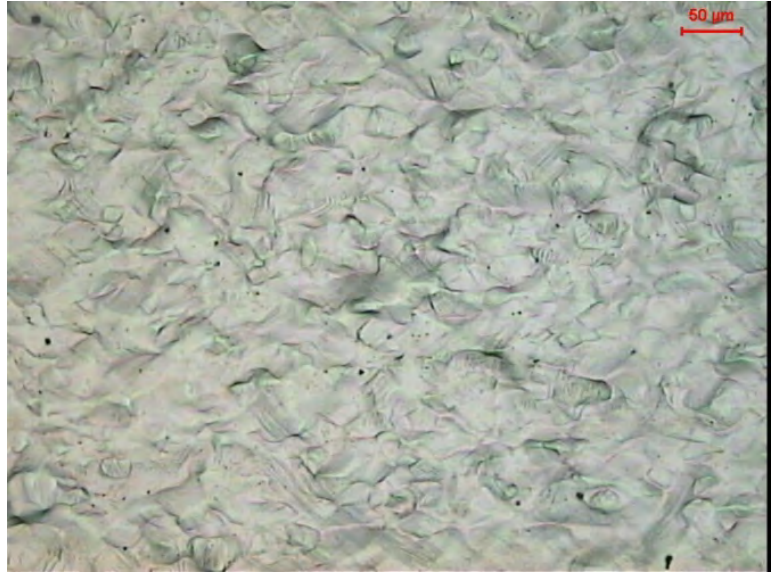

(b)

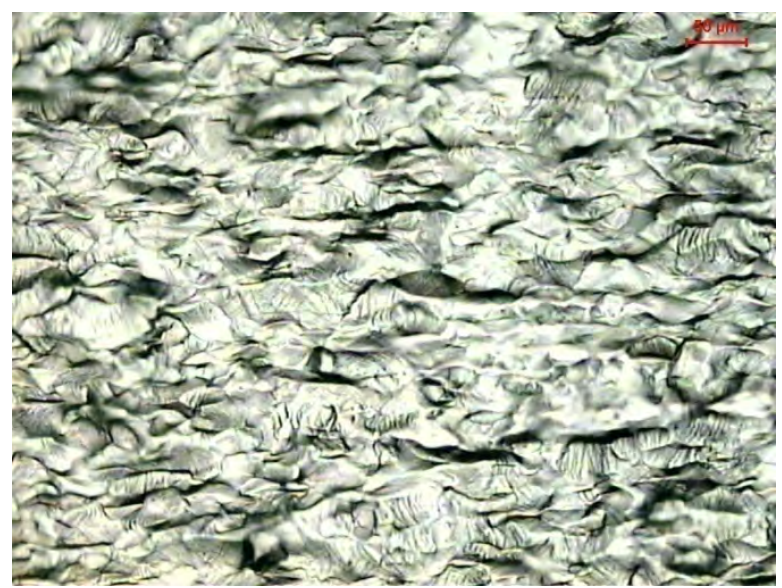

(d)

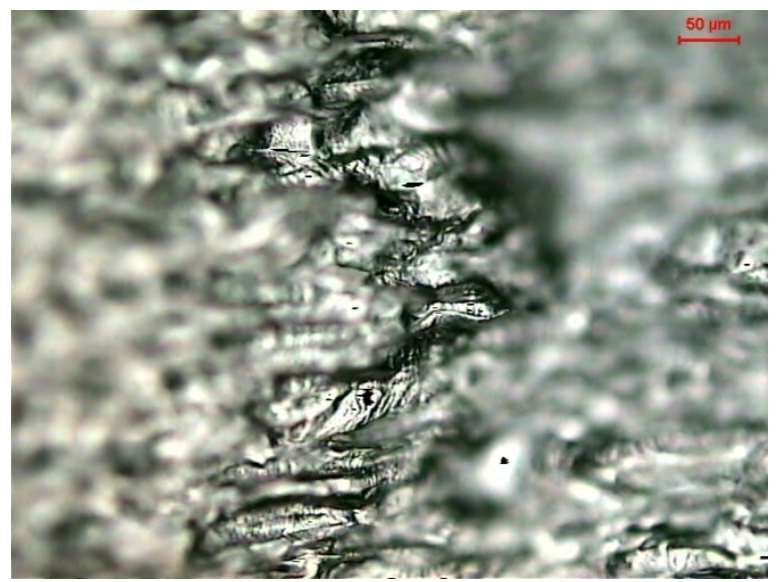

(f) 
Pode-se observar que quanto maior a deformação experimentada pelos corpos de prova, maiores os danos causadosà superfície. Estes danos não se manifestaram na forma de microcavidades observáveis por microscopia óptica, mas sim por meio de aumento da rugosidade superficial, causada pelos deslizamentos de planos atômicos que, em uma escala microscópica, se manifestaram por meio das linhas de deformação. Para as amostras intensamente deformadas, as superfícies irregulares dificultaram o ajuste do foco. Estas observações estão de acordo com a literatura e as linhas de deformação observadas apresentam as mesmas características apontadas por diversos pesquisadores.

A Figura 5 apresenta a evolução de danos medida indiretamente pela rugosidade das superfícies (IDRD) em função da deformação. Nota-se que o corpo de prova com $0 \%$ de deformação, que corresponde ao estado de entrega,não possui danos. O corpo deformado de 1,2\%, portanto ainda dentro do regime de deformação elástica, também não apresentou danos medidos pela técnica proposta. Para os demais pontos correspondentes às deformações crescentes no regime de deformação plástica, observa-se que a porcentagem de danos aumenta com o alongamento percentual experimentado pelos corpos de prova.

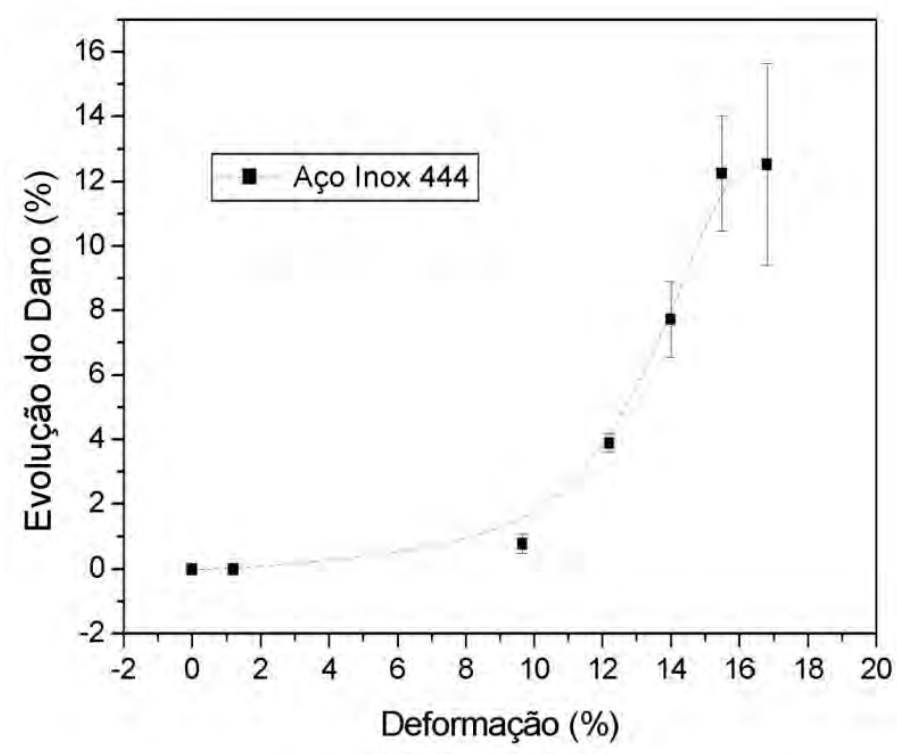

Figura 5 - Evolução de danos em função do nível de deformação no ensaio de tração.

Na Figura 5 também se pode notar que a taxa variacional da evolução de danos em relação à deformação aumenta significativamente para valores de deformação superiores ao correspondente à tensão limite de resistência do material (12,2\%). Isto pode ser justificado pelo fato de que para tensões superiores a esta, há um relaxamento da estrutura do material e conseqüentemente a deformação não uniforme e a fratura. Observa-se ainda que o desvio padrão da médiacresce com o aumento da deformação, pois a evolução de danos torna-se mais intensa e localizada. Neste contexto uma varredura sobre a superfície do corpo de prova para a determinação do índice IDRD leva a uma variação mais acentuada dos valores obtidos justificando o aumento do desvio.

As amostras submetidas às maiores deformações foram submetidas a análises por meio de microscopia eletrônica de varredura. As Figuras 6a, 6b, 6c e 6d apresentam micrografias das superfícies deformadas de $9,7 \%, 12,2 \%, 14 \%$ e $16 \%$ respectivamente. Em todas estas figuras observa-se a presença de bandas de deformação alinhadas em curto alcance, porém com diferentes sentidos a médio e 
longo alcance.Isto pode ser justificadopelo fato de que cada grão do material possui uma diferente orientação cristalina, e pode se deformar com maior ou menor facilidade a depender da orientação e da carga aplicada sobre o material.

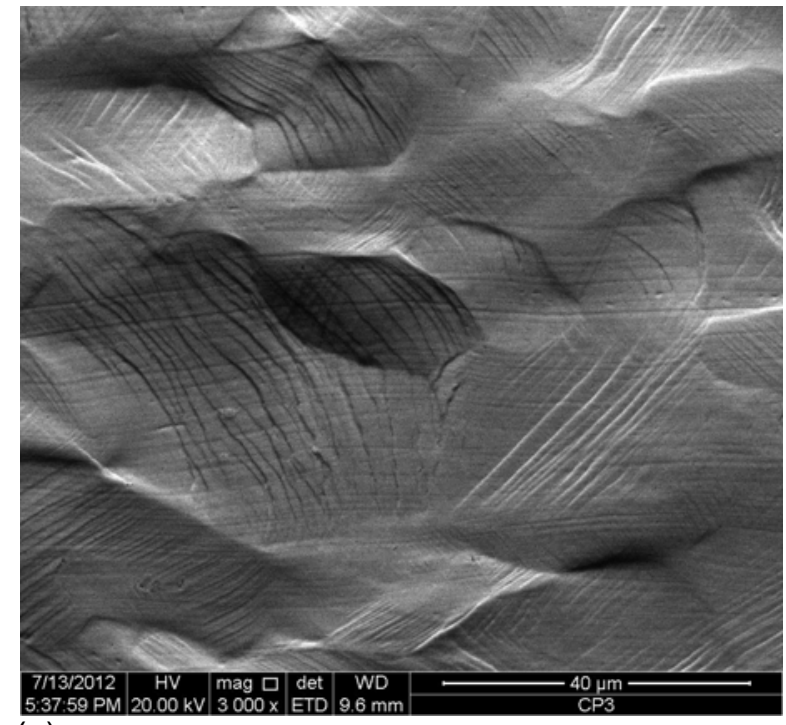

(a)

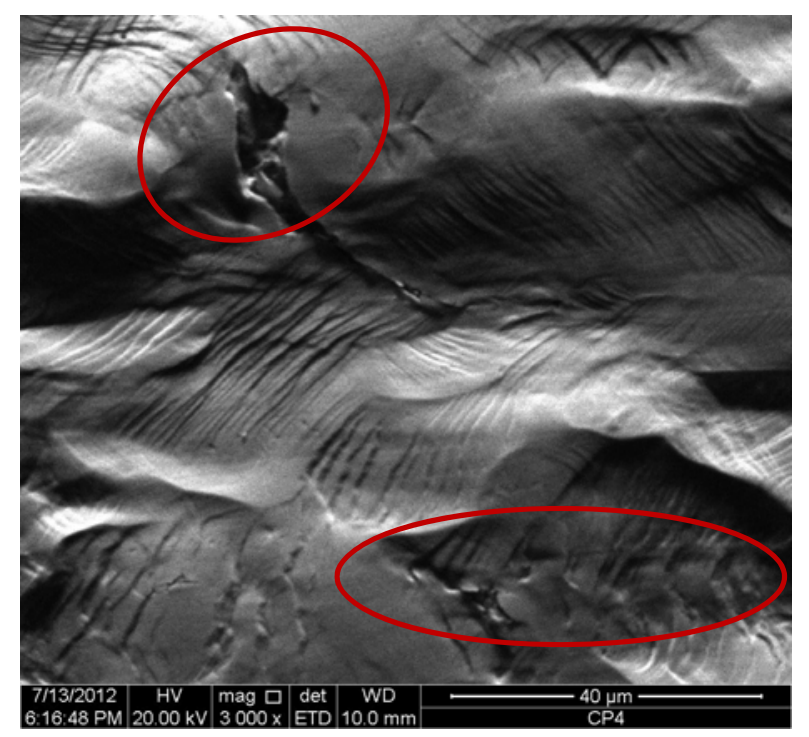

(c)

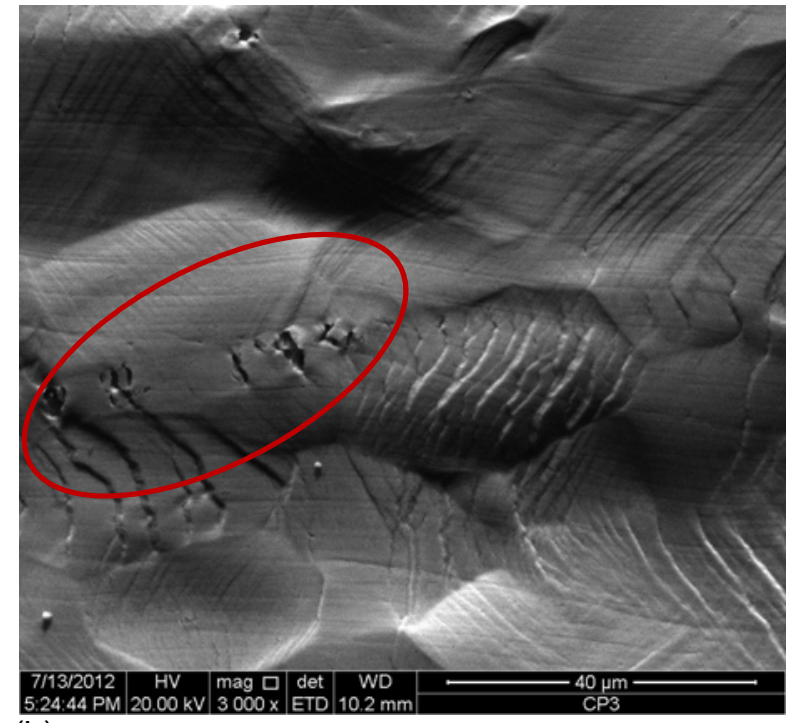

(b)

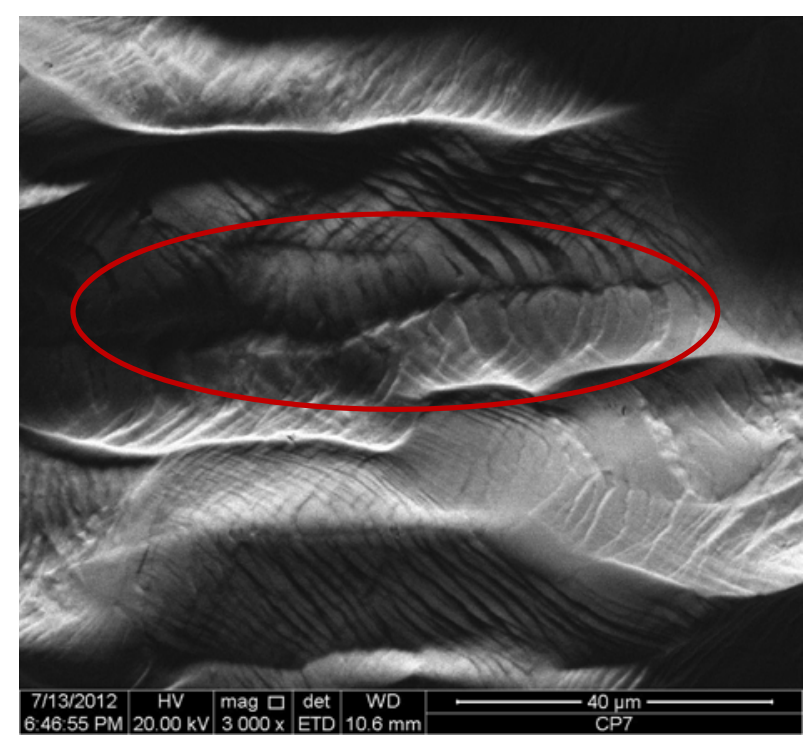

(d)

Figura 6 - Superfícies dos corpos de prova de tração. (a) Deformação de 9,7\%. (b) Deformação de 12,2\%. (c) Deformação de 14\%. (d) Deformação de 16\%. 3000X. MEV.

$\mathrm{Na}$ Figura 6b, observa-se, além das bandas de deformação, a nucleação de microcavidades (mostradas na elipse). Deve-se destacar que esta figura corresponde a 12,2\% de deformação, ou seja, deformação a partir da qual este material entra no regime de deformação plástica não uniforme. Nota-se que para o aço AISI 444 nas condições estudadas, as microcavidades têm origem a partir das linhas de deformação. Esta observação é sustentada pela literatura, uma vez que trabalhos como os de Puttick, ${ }^{(8)}$, Rogers, ${ }^{(9)}$ Chen $^{(10)}$ e Beevers E Honeycomb ${ }^{(11)}$ já apontavam as linhas de deformação como região potencial para nucleação de vazios. Não foram observadas significativas formação de microcavidades nas heterogeneidades presentes no material estudado (pequena fração de inclusões). 
A Figura 6c, referente a uma deformação de 14\%, apresenta cavidades maiores, provavelmente provenientes do coalescimento de cavidades menores, como descrito na literatura. A Figura $6 \mathrm{~d}$, referente a deformação de $16 \%$, apresenta a origem de uma trinca proveniente do coalescimento de microcavidades.Estas observações apontam o mecanismo de fratura dúctil como uma sequência de nucleação, crescimento e coalescimento de microcavidades, conforme sugerido pela literatura. Com o objetivo de caracterizar a fratura do aço AISI 444 em tração e comprovar a relação entre a evolução de danos microestruturais e o mecanismo de fratura dúctil, as amostras ensaiadas até a fratura foram submetidas a análises fractográficas por meio de microscopia eletrônica de varredura, e pôde-se observar a presença de dimples, o que finalmente confirmou a fratura como sendo dúctil. A Figura 7 apresenta as fractografias em questão.
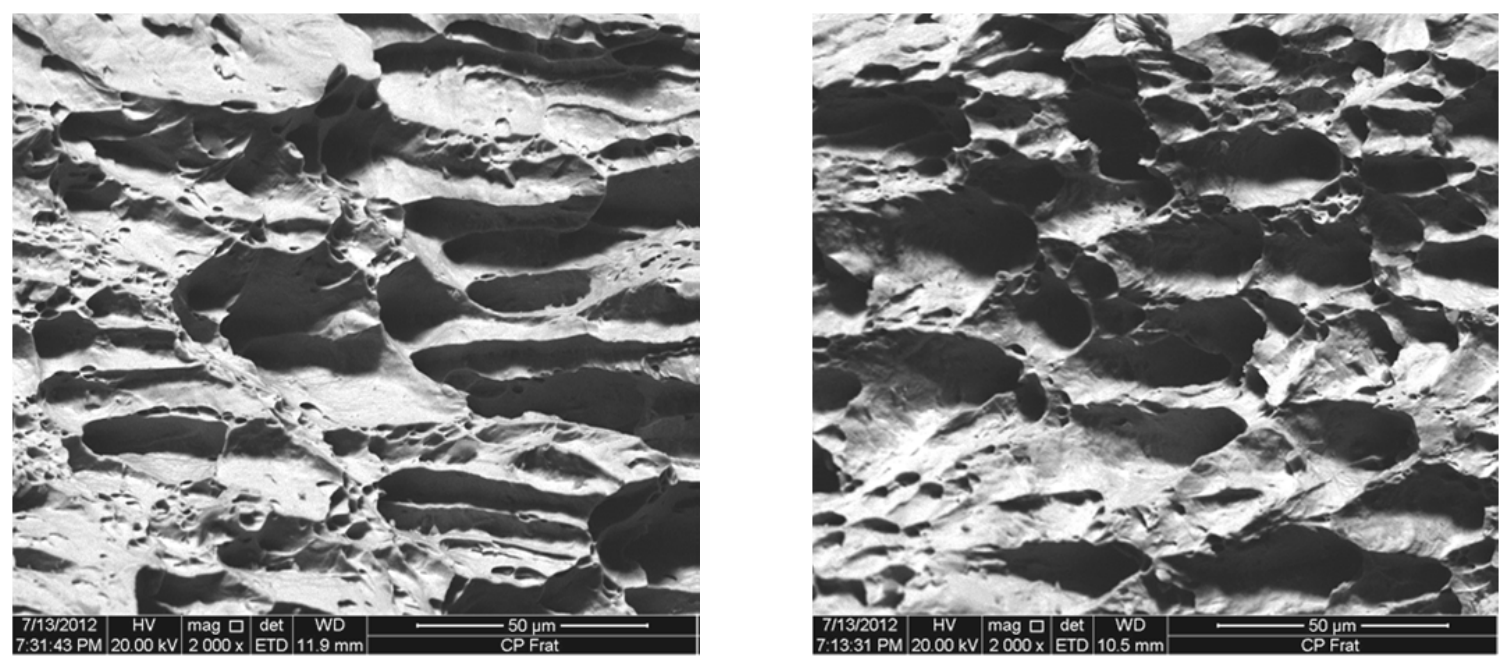

Figura 7 - Fractografias dos corpos de prova de tração confeccionados a partir do aço AISI 444. 2000X. MEV.

\section{CONCLUSÕES}

O método proposto para a avaliação de danos pelo índice IDRD foi satisfatório, pois permitiu quantificar e comparar as diferentes intensidades de danos como função da deformação sofrida pelo corpo de prova.

O índice IDRD proposto pode ser uma ferramenta em potencial, de fácil aplicação e baixo custo experimental, para associada à caracterização estrutural por microscopia óptica e eletrônica de varredura caracterizar a evolução de danos microestruturais em diferentes materiais metálicos, possibilitando descrever os mecanismos de fratura em função de diferentes parâmetros como fração de inclusões, tamanho de grão, proporção de fases e constituintes entre outros.

O aço inoxidável ferrítico AISI 444 apresenta fratura do tipo dúctil quando ensaiado em tração, sendo a nucleação, o crescimento e coalescimento de microcavidades a partir das linhas de deformação o principal mecanismo de fratura.

\section{Agradecimentos}

Os autores agradecem a empresa Aperam do Brasil por ceder gentilmente os corpos de prova. 


\section{REFERÊNCIAS}

1 ROSENFIELD, A. R. Criteria for Ductile Fracture of Two-phase Alloys. International Materials Reviews, vol. 13, N 1, pp. 29-40(12). 1968.

2 LOW, J. R. Eng. Fract. Mech.1, 47. 1968.

3 SCHWALBE, K. On the Influence of Microstructure on Crack Propagation Mechanisms and Fracture Toughness of Metallic Materials. Engineering Fracture Mechanics. Vol. 9, Issue 4, pp. 795-832. 1977.

4 HOWARD and WILLOUGHBY, A. A. Developments in Fracture Mechanics. Applied Science. p.39. 1981.

5 WILSDORF, H. G. F. The Ductile Fracture of Metals: A Microstructural Viewpoint. Materials Science and Engineering, 59 (1983) 1-39. 1982.

6 VAN STONE, R. H; COX, T. B; LOW, J. R; and PSIODA, J. A. Microstructural Aspects of Fracture by Dimple rupture. InternationalMetalsReviews. Vol. 30. pp. 157-180. 1985.

7 GODEFROID, L. B; BASTIAN F. L. Uma Análise Crítica sobre Modelos que envolvem a Influência de Inclusões na Fratura Dúctil. In: 44 Congresso Anual da ABM, 1989, Rio de Janeiro. Anais do $44^{\circ}$ Congresso Anual da ABM, 1989. v. 1. pp. 471-493.

8 PUTTICK, K. E. Ductile Fracture in Metals. Philosophical Magazine. Vol. 4. pp. 964-969. 1959.

9 ROGERS, H.C.The Tensile Fracture of Ductile Metals. Trans. Amer. Inst. Min. (metal) Engrs, 216, pp. 498-506. 1960.

10 CHEN, C. W. Void Formation in Ductile Fracture of a Cobalt-iron Alloy. Acta Met. Vol. 9.pp. 68-71. 1961.

11 BEEVERS, C. J; HONEYCOMB, W. K. The Initiation of Ductile Fracture in Pure Metals.Philosophical Magazine, vol. 7, issue 77, pp. 763-773. 1962.

12 EDELSON B. I; BALDWIN, W. M. The Effect of Second Phases on the Mechanical Properties of Alloys. Trans. ASM, 60, 672. 1962.

13 COX, T. B; LOW, J. R. An investigation of the plastic fracture of AISI 4340 and 18 Nickel200 grade maraging steels. Metall. Trans. 5A, 1457. 1974.

14 ARGON A. S; IM, J; NEEDLEMAN, A. Cavity Formation from Inclusions in Ductile Fracture. Metall. Trans. 6A, 825. 1975.

15 ARGON A. S. J. Eng. Mater. Technol. (Trans. ASME), 98, 60. 1976.

16 SHOCKEY, D. A; SEAMAN, K. C; DAO, K. C. A Computational Fracture Model for SA533 Grade B Class 1 Steel Based Upon Microfracture Process. Report NP-701-SR. Electric Power research Institute. 1978.

17 FLOREEN S; HAYDEN, H. W. Some Observations of Void Growth during the Tensile Deformation of a high strength steel. Scr. Metall. 4, 87. 1970.

18 COTTRELL, A. H. in Fracture, (ed. B. L. Averbach et al), 20; Technology Press of MIT and Wiley. 1959.

19 DRUYRESTEYN M. H. et al. J. Mech. Phys. Mater. 12, 219. 1964.

20 CRUSSARD C. et al. In: AVERBACH, B. L. et al. (eds.). Fracture. Technology Press of MIT and Wiley. 1959.524

21 KADKHODAPOUR, J; BUTZ, A; RAD, S. Z; Mechanisms of Void Formation During Tensile Testing in a Commercial Dual Phase Steel. ActaMaterialia, vol 59, pg 2574-2588. 2011.

22 APERAM, Catálogo aço inoxidável AISI 444, 2012. 